\title{
Sob nova direção: O PNLD e seus desafios frente aos contextos político-educativos emergentes
}

Under New Direction: Brazilian PNLD and its Challenges in the Emerging Political-Educational Context

Flávia Eloisa Caimi * ${ }^{*}$

\section{RESUMO}

Pela sua importância e dimensão no cenário educacional brasileiro, o Programa Nacional do Livro Didático (PNLD) tem o mérito de submeter a produção didática a processos avaliativos sistemáticos e sólidos, contribuindo para a melhoria da qualidade dos materiais que se destinam aos diversos níveis da educação básica em instituições públicas brasileiras. No estudo ora proposto, de natureza bibliográfica e documental, intenta-se: a) analisar os caminhos recentes dessa política pública que tem se configurado como programa de Estado; b) sistematizar alguns dos principais avanços conquistados nas últimas duas décadas; e c) apontar seus desafios frente à publicação do Decreto 9.099/2017, no momento em que o país vive um contexto político-educativo marcado por fortes disputas em torno do papel do Estado na promoção da redistribuição de bens públicos, da cidadania e da justiça social. Palavras-chave: PNLD; mercado editorial; sistema estruturado de ensino.

\begin{abstract}
Considering its importance and dimension in the Brazilian educational scenario, the National Textbook Program (PNLD) has the merit of evaluating the didactic production through systematic and solid review processes, contributing to improve the quality of the materials that are destined to the different levels of basic education in Brazilian public institutions. In the present study, from bibliographical and documentary basis, the purpose is to: a) analyze the recent paths of this public policy that has been considered as a State program; b) systematize some of the major advances made over the last two decades; and c) point out its challenges in light of the publication of Decree 9099/2017, considering a moment in which the country lives in a political-educational context marked by strong disputes over the role of the State in promoting redistribution of public goods, citizenship, and social justice.
\end{abstract}

Keywords: PNLD; publishing market; structured teaching system.

* Programa de Pós-Graduação em Educação da Universidade de Passo Fundo (UPF), Passo Fundo, RS, Brasil. caimi.flavia@gmail.com 
Toda e qualquer política educativa entendida como a ação do Estado propriamente dita deve ter a precípua finalidade de garantir o direito à educação para crianças, jovens e adultos, fomentando as condições necessárias para que a escola se configure como um espaço de acesso universal, onde se ensine melhor e se aprenda mais. Em um país de dimensões continentais como o Brasil, em que a diversidade social e cultural é, frequentemente, sinônimo de desigualdade econômica, estabelecer políticas educacionais públicas de equalização representa o compromisso do Estado com a inclusão, a cidadania e a justiça social. O Programa Nacional do Livro Didático (PNLD) é uma iniciativa que se insere nessa perspectiva, no esforço de oportunizar que todos os alunos que frequentam a escola pública brasileira contem com o aporte de livros didáticos na quase totalidade das disciplinas escolares, de modo a assegurar o acesso aos livros, contribuir com a formação de leitores e criar condições de apropriação dos saberes e conhecimentos disciplinares em patamares qualificados.

Os números do PNLD 2017 disponibilizados pelo Fundo Nacional de Desenvolvimento da Educação (FNDE) ${ }^{2}$ mostram que foram beneficiadas 117.690 escolas de ensino fundamental e médio, um total de 29.416.511 alunos receberam 152.351.763 exemplares de livros didáticos, o que resultou num investimento financeiro de $\mathrm{R} \$ 1.295 .910 .769,73$. Trata-se, portanto, de um programa de largo alcance, que mobiliza vultosos recursos e atinge um contingente expressivo de sujeitos: alunos, professores, gestores e famílias. Concerne, ainda, a uma estratégia de amparo à política educacional de caráter obrigatório, prevista no Artigo 208, Inciso VII, da Constituição Federal de 1988, nestes termos: "O dever do Estado com a educação será efetivado mediante a garantia de [...] atendimento ao educando, em todas as etapas da educação básica, por meio de programas suplementares de material didático-escolar, transporte, alimentação e assistência à saúde” (Brasil, 1988, s. p.). Assim, mais do que um direito das gerações a uma escolarização gratuita e de qualidade, o fornecimento de material didático, transporte, merenda escolar e assistência à saúde é uma forma obrigatória de o Estado brasileiro cumprir com o seu dever em matéria de educação, por meio de programas suplementares. Há quase duas décadas, Höfling (2000, p. 160) já alertava para a reconfiguração dos programas de assistência ao estudante antes vigentes: "de caráter assistencial, conjuntural, adquirem pelo preceito constitucional caráter 
universalizante, obrigatório, destinados e garantidos a todos aqueles que têm, igualmente, direito ao acesso à educação, pelo menos em termos legais”.

Longe de solucionar todas as limitações que permeiam a produção didática ou de dar respostas a todas as encorpadas críticas que lhe são direcionadas, pode-se afirmar que do ponto de vista da avaliação, foco do presente artigo, o PNLD teve o mérito, ao longo dos últimos 20 anos, de submeter a produção editorial a processos avaliativos sistemáticos e solidamente organizados, eliminando e/ou amenizando um conjunto de restrições historicamente presentes nesse suporte cultural nomeado livro didático. Em seu percurso, o PNLD atravessou diversas gestões presidenciais mantendo a concepção básica de que o Estado deve dedicar atenção aos processos de avaliação, aquisição e distribuição de livros didáticos - e, ao fazê-lo, estabelece critérios que incidem também sobre os processos de produção e editoração -, assegurando as condições para que os estudantes da educação básica recebam livros cada vez mais qualificados.

Assumido e consolidado como Programa de Estado no âmbito da legislação desde a publicação do Decreto 7.084/2010 (Brasil, 2010), o PNLD consolidou um conjunto de diretrizes formuladas ao longo de mais de duas décadas, que podem ser sumarizadas nos seguintes aspectos, dentre outros: o respeito ao pluralismo de ideias e concepções pedagógicas; o respeito às diversidades sociais, culturais e regionais; o respeito à autonomia pedagógica dos estabelecimentos de ensino; o respeito à liberdade e o apreço à tolerância; e a garantia de isonomia, transparência e publicidade nos processos de avaliação, seleção e aquisição das obras (Brasil, 2010, p. 1). A avaliação dos livros ocorre anualmente, mediante publicação de editais que apresentam critérios consistentes e transparentes, contando com equipes avaliativas que atendem à diversidade nacional, composta de professores dos diversos níveis da educação básica e da educação superior, provenientes de diferentes regiões do Brasil. A heterogeneidade da procedência na composição das equipes avaliadoras tem contribuído para a mobilização de inúmeros saberes e práticas culturais no processo avaliativo, incorporando as diferentes visões e necessidades que se impõem sobre o livro didático nos mais variados espaços e culturas regionais.

Com vistas a aprimorar os processos de publicização e transparência, instaurou-se em 2015 a prática da chamada pública para contratação das universidades responsáveis pela avaliação pedagógica, antes efetuadas no âmbito 
do Ministério da Educação (MEC), com a indicação de especialistas que compunham a Comissão Técnica dos respectivos componentes curriculares. $\mathrm{Na}$ mesma direção, procedeu-se a mudanças na composição dos pareceristas, que passaram a ser sorteados de um Banco de Avaliadores, constituído por professores de todos os níveis e áreas, com prévia inscrição.

Ao longo dos últimos 20 anos, especialmente a partir de 1996, quando o PNLD foi redimensionado e configurado num modelo contínuo e sistemático de avaliação, com aporte de recursos orçamentários, a qualidade do livro didático foi alavancada em todas as disciplinas. Tratando especificamente do livro de História, nosso foco de investigação, podem-se mencionar como algumas das principais conquistas: a minimização de erros conceituais, de anacronismos e simplificações explicativas; a supressão de situações de estereótipos e preconceitos; os avanços na atualização de conteúdos e aperfeiçoamentos na produção gráfica e visual dos livros; as mudanças de concepção editorial com textos mais breves, intercalados por muitas imagens, mapas, atividades, quadros, tabelas, resumos; a escrita do texto com estilo mais polifônico, contemplando o cotejo de versões historiográficas e a incorporação de excertos de obras de autores acadêmicos; a ênfase no trabalho com múltiplas temporalidades, no esforço de focalizar temáticas para o estudo do passado a partir das questões e problemas do tempo presente; as indicações e remissões frequentes para materiais complementares em suportes digitais (sites, livros digitais, vídeos); o investimento mais acentuado nas orientações ao docente para fazer o melhor uso do livro didático, oferecendo o Manual do Professor como espaço de formação continuada e de reflexão sobre a prática; a presença de documentos históricos diversos, cada vez mais sendo tratados em sua condição de fonte, indo além de abordagens meramente ilustrativas e/ou comprobatórias; a abordagem mais constante e intensificada de temas transversais (meio ambiente, educação para a paz, educação para as relações étnico-raciais, pluralidade cultural) junto da narrativa histórica; o fortalecimento da legislação referente à história e cultura africana, afro-brasileira e indígena (Leis 10.639/2003 e 11.645/2008), ao Estatuto do Idoso, ao Estatuto da Criança e do Adolescente, dentre outras, e também o cuidado com as políticas de ações afirmativas, como, por exemplo, a valorização da mulher, o combate à violência de gênero, à homofobia e à transfobia (Caimi, 2017). 


\section{Os CAMINHOS DO PNLD SOB UMA NOVA}

AGENDA: O DECRETO 9.099/2017

No mês de abril de 2016 foi instalado na Câmara dos Deputados um processo de impeachment contra a presidente Dilma Rousseff, que fora reeleita no segundo turno em 2014 com um percentual de 51,64\% dos votos válidos, totalizando em torno de 54,5 milhões de votos. No mês de agosto do mesmo ano, ao final do processo de julgamento político por supostas "pedaladas fiscais", a presidente foi deposta, passando a ocupar o cargo o vice-presidente Michel Temer. Desde então, uma nova agenda para o país tem sido implementada, levando a cabo um projeto bastante distinto daquele que fora eleito pela maioria da população brasileira. Temos enfrentado inúmeras ameaças e sequestros de direitos em diversos setores, que reforçam a concessão de privilégios para poucos e aprofundam as desigualdades sociais no nosso país. Ramos e Frigotto (2016, p. 35) analisam esse novo cenário político-educacional com base nesta constatação:

O âmbito onde a organicidade de classe melhor se explicita é o campo da educação, terreno da formação das novas gerações. Com efeito, não por acaso, o Movimento Escola sem Partido começou em 2004 e o Movimento Todos pela Educação em 2005 - ainda que oficializado em 2006 no lançamento do Plano de Desenvolvimento da Educação (PDE). O primeiro foi elaborando e explicitando o sentido contrário de como se define. Vale dizer, a ideologia do partido do pensamento único - da neutralidade do conhecimento, do ensino e da educação, mas acrescido, agora, da intolerância e ódio ao diferente. O segundo, criado por catorze dos maiores grupos econômicos ligados à indústria, ao capital financeiro e ao agronegócio; e por dezoito parceiros, estes operadores, em especial nos sistemas municipais e estaduais de educação na disputa concreta do conteúdo, métodos e valores que interessam ao mercado.

Medidas que incidem diretamente sobre a educação - portanto, sobre a vida das pessoas - ou que impactam sobre ela de forma indireta, são implementadas de forma célere, sem nenhum diálogo com o conjunto da sociedade. No segundo caso, o exemplo mais contundente é a promulgação da Emenda Constitucional 241/2016, que limita por 20 anos o teto dos gastos públicos e, consequentemente, afetará as políticas públicas que beneficiam expressamente 
as camadas da população que mais necessitam delas. Essa emenda reduzirá investimentos em saúde e educação, impactará o salário mínimo, mas não incidirá sobre o pagamento dos juros da dívida pública, por exemplo.

No caso da educação, em sentido estrito, um dos exemplos mais preocupantes é a efetuação de ampla Reforma no Ensino Médio que tramitou inicialmente por meio da Medida Provisória 746, de 22 de setembro de 2016, sendo convertida, menos de 5 meses depois, na Lei 13.415, de 16 de fevereiro de 2017. Essa lei reconfigura profundamente a estrutura e os desenhos curriculares do ensino médio, cujo cerne "está na dissociação entre ensinar e educar e na condução de um processo de ensino com base na fragmentação e no pragmatismo". Ademais, reitera "a dualidade educacional e o acesso desigual ao conhecimento e à cultura, de acordo com a classe social” (Ramos; Frigotto, 2016, p. 44).

Tendo em vista o foco deste estudo, que se debruça sobre as mudanças recentes do Programa Nacional do Livro Didático (PNLD) realizadas após o impeachment de 2016 e protagonizadas pelos "novos donos do poder", como diz Laville (1999), trataremos agora das alterações e possíveis impactos do Decreto 9.099, de 18 de julho de 2017, que dispõe sobre o Programa Nacional do Livro e do Material Didático (Brasil, 2017), em caráter comparativo ao Decreto anterior, 7.084/2010 (Brasil, 2010). Num primeiro olhar, algumas alterações se mostram inofensivas à natureza e à qualidade do programa, ao passo que outras devem ser cuidadosamente avaliadas, por conterem potenciais danos aos princípios de democracia, equalização de direitos, cidadania e justiça social.

Já no Art. $1^{\circ}$ do Decreto 9.099/2017 identificam-se alterações relevantes. Vejamos a íntegra do Artigo:

Art. $1^{\circ}$ - O Programa Nacional do Livro e do Material Didático - PNLD, executado no âmbito do Ministério da Educação, será destinado a avaliar e a disponibilizar obras didáticas, pedagógicas e literárias, entre outros materiais de apoio à prática educativa, de forma sistemática, regular e gratuita, às escolas públicas de educação básica das redes federal, estaduais, municipais e distrital $e$ às instituições comunitárias, confessionais ou filantrópicas sem fins lucrativos e conveniadas com o Poder Público. (Brasil, 2017, p. 7, grifos nossos)

Ao fixar no PNLD a tarefa de avaliar e disponibilizar obras didáticas, pedagógicas e literárias, o Decreto estabelece a fusão entre dois programas que 
se desenvolviam por caminhos distintos: o Programa Nacional do Livro Didático (PNLD) e o Programa Nacional Biblioteca da Escola (PNBE), que se destina à avaliação e distribuição de acervos de obras de literatura, de pesquisa e de referência a estudantes e professores da educação básica, com vistas ao incentivo à leitura e promoção do acesso à cultura. Resulta dessa fusão não só uma nova nomenclatura, passando o PNLD a denominar-se Programa Nacional do Livro e do Material Didático, mas também a possibilidade de o programa avaliar, adquirir e distribuir outros materiais de apoio à prática educativa. O que se pode vislumbrar com essa expressão tão genérica (outros materiais) é a inclusão de softwares, jogos educacionais, dicionários, materiais de apoio e correção de fluxo (defasagem série-idade), ações já contempladas no decreto anterior, bem como a abertura da possibilidade de o Estado brasileiro adquirir e distribuir os chamados sistemas estruturados de ensino (ou sistemas apostilados, como usualmente se diz), numa associação estreita com os grandes grupos privados, conhecidos pelas práticas de mercantilização da educação. Ainda, na sequência do Artigo $1^{\circ}$, faculta-se a distribuição de materiais não só às redes públicas, mas também "às instituições comunitárias, confessionais ou filantrópicas sem fins lucrativos”. A esse tópico da participação do mercado privado no espaço público nos dedicaremos com especificidade, em seção subsequente. Por ora, seguiremos com a identificação das alterações apresentadas no novo Decreto.

No Artigo $2^{\circ}$, Inciso VI, estabelece-se uma vinculação direta e unívoca entre a Base Nacional Comum Curricular (BNCC) e o Livro Didático. Note-se que à época da publicação do Decreto (julho de 2017) a BNCC do Ensino Fundamental ainda não estava em vigor, tendo sido aprovada apenas em 15 de dezembro de 2017. O mesmo ocorria com a BNCC do Ensino Médio, aprovada tão somente no ano seguinte, em dezembro de 2018. Ao exigir, por decreto, que o livro didático contemple as proposições da BNCC, retira-se a prerrogativa de oferecer abordagens de diferentes matrizes do conhecimento, atrelando-o a um desenho curricular preestabelecido. Ainda que o livro didático, ao longo dos anos, tenha sofrido um movimento de uniformização de conteúdos e abordagens por força dos editais do PNLD, ${ }^{3}$ entende-se que com a sua vinculação estrita à BNCC tenderemos a uma homogeneização sem precedentes, transformando o livro didático não só no currículo editado (Escolano Benito, 2006), mas no currículo prescrito, subsidiando as avaliações de larga 
escala, os exames padronizados e, consequentemente, os rankings de rendimento dos estudantes.

Pelo Decreto 9.099/2017 ampliou-se o atendimento a outros segmentos e disciplinas, passando a contemplar com materiais didáticos também a educação infantil e o componente curricular Educação Física no ensino fundamental. Ademais, alterou-se o modo de definir o ciclo dos processos avaliativos, passando a estabelecer a vigência em Edital, a cada ciclo, segundo o interesse do Ministério da Educação (MEC) e do Fundo Nacional de Desenvolvimento da Educação (FNDE). No Decreto 7.084/2010, os ciclos de atendimento (avaliação e escolha) ocorriam a cada 3 anos, nos respectivos segmentos: (1) anos iniciais do ensino fundamental; (2) anos finais do ensino fundamental e (3) ensino médio. No Edital PNLD 2019, destinado aos anos iniciais do ensino fundamental, o primeiro sob a vigência do novo Decreto, o ciclo foi determinado em 4 anos, podendo ser alterado para 6 anos em outros editais. Os impactos dessas proposições terão de ser bem avaliados nos próximos anos, mas se pode pressupor, de antemão, que elas repercutirão diretamente na sala de aula. Não é difícil supor que, com o aumento do prazo do ciclo de vigência daquele processo avaliativo, os estudantes terão livros mais defasados e desatualizados ao final dos 4 anos do ciclo. Ou seja, ainda que sejam repostos anualmente, uma vez que são consumíveis, a escolha de novos livros pelos professores só poderá ser feita após o fim do ciclo de atendimento. Na lógica mercantil, que parece reger muitas dessas mudanças, um ano a mais no ciclo representa, ao final de três ciclos, uma economia financeira considerável.

Quanto à escolha dos integrantes da Comissão Técnica dos respectivos componentes curriculares, antes selecionados pelo MEC dentre os profissionais portadores de titulação e especialização compatível com as demandas avaliativas de cada área/disciplina, passa a ser feita a partir da indicação de um conjunto de Instituições e Entidades, a saber: Secretaria de Educação Básica do Ministério da Educação; Conselho Nacional de Secretários de Educação; União Nacional dos Dirigentes Municipais de Educação; União Nacional dos Conselhos Municipais de Educação; Fórum Nacional dos Conselhos Estaduais de Educação; Conselho Nacional de Educação; Associação Nacional dos Dirigentes das Instituições Federais de Ensino Superior; Conselho Nacional das Instituições da Rede Federal de Educação Profissional, Científica e Tecnológica; Entidades da sociedade civil escolhidas pelo Ministério da 
Educação para elaboração das listas tríplices do Conselho Nacional de Educação, conforme o disposto no Decreto 3.295, de 15 de dezembro de 1999 (Brasil, 2017, p. 7-8).

Outro aspecto, relacionado com o anterior, que altera fundamentalmente a dinâmica do PNLD diz respeito ao papel das universidades nos processos avaliativos. No Decreto 7.084/2010, em seu Artigo 14, consta que "a avaliação pedagógica das obras será realizada por instituições de educação superior públicas, de acordo com as orientações e diretrizes estabelecidas pelo Ministério da Educação, a partir das especificações e critérios fixados no edital correspondente" (Brasil, 2010, p. 6). No parágrafo primeiro desse mesmo Artigo afirma-se que "para realizar a avaliação pedagógica, as instituições de educação superior públicas constituirão equipes formadas por professores do seu quadro funcional, professores convidados de outras instituições de ensino superior e professores da rede pública de ensino" (Brasil, 2010, p. 6).

No Decreto 9.099/2017, por sua vez, fica reservado ao Ministério da Educação o papel de constituir, em forma de edital, as regras a serem obedecidas no âmbito da avaliação pedagógica, retirando das universidades a condução dessa etapa avaliativa. Mais especificamente, no parágrafo primeiro se estabelece que "para realizar a avaliação pedagógica, serão constituídas equipes de avaliação formadas por professores das redes públicas e privadas de ensino superior e da educação básica" (Brasil, 2017, p. 8). Essa alteração confere prejuízo ao processo avaliativo, na medida em que destitui o papel da universidade pública, cuja competência na produção intelectual de caráter teórico-metodológico e na formação de professores é amplamente reconhecida. A centralização do processo avaliativo no Ministério da Educação, coordenado por agentes técnicos, tende a fragmentar a avaliação do conjunto da produção didática, instituindo uma avaliação isolada de cada obra, de modo a desfavorecer possibilidades de análises mais amplas do cenário editorial e educacional, nas diversas áreas do saber. Ademais, faz incidir mais fortemente sobre o PNLD as demandas imediatistas e as pressões mercadológicas pela disputa em torno dos recursos públicos, o que pode levar à maior flexibilização de critérios quanto à qualidade do livro e do material didático. Ninguém desconhece a enorme importância dos programas governamentais de aquisição de livros didáticos para o mercado editorial brasileiro, os oligopólios formados pelas editoras para vender livros ao FNDE e a abrangência da demanda do Estado, que responde 
por cerca de $90 \%$ da compra de livros didáticos do ensino fundamental, por exemplo. Dessa questão nos ocuparemos mais detidamente, adiante.

Uma das conquistas mais importantes do PNLD ao longo dos anos diz respeito à escolha dos livros na escola e pelos professores. Essa prerrogativa foi ratificada no Decreto 7.084/2010, em seu Artigo 24, nos seguintes termos: “Os livros didáticos serão livremente escolhidos pela escola, por meio de seu corpo docente e dirigente, em primeira e segunda opção para cada componente curricular, considerando-se a adequação e a pertinência das obras em relação à proposta pedagógica de cada instituição escolar" (Brasil, 2010). No Decreto 9.099/2017, todavia, a liberdade de escolha pelo professor na escola é severamente restringida, na medida em que abre possibilidade de a escolha ser única para toda a rede. Isso está estabelecido no Art. 18, com esta redação: “Durante a etapa de escolha, por opção dos responsáveis pela rede, a adoção do material didático será única: I - para cada escola; II - para cada grupo de escolas; ou III - para todas as escolas da rede" (Brasil, 2017). Note-se que ao alargar o âmbito da escolha para grupos de escolas ou para todas as escolas da rede, o decreto permite que as secretarias municipais e as secretarias estaduais de educação constituam comissões para seleção única do livro didático de cada componente curricular. Permite, portanto, que as escolhas sejam permeadas por outras razões que não as necessidades das escolas, seus projetos pedagógicos específicos e as propostas curriculares e metodológicas dos professores de determinada escola.

O PNLD vinha se pautando pela ideia de que a seleção do livro didático diz respeito à especificidade do trabalho de cada professor, que reflete também a sua concepção de ensino, os objetivos com a disciplina e uma determinada organização de conteúdos que julga mais adequada naquele contexto em particular. Não obstante, esse alargamento de competências abre brechas para imposições dos dirigentes políticos, num contexto em que, tradicionalmente, preponderam interesses de ordem econômica e político-partidária. A escolha homogeneizada para um município ou estado representa, portanto, o esvaziamento da liberdade de escolha do professor sobre o livro didático, este que é, possivelmente, o mais relevante entre os materiais que subsidiam a sua proposta didático-pedagógica.

Considerando o conjunto das alterações estabelecidas no novo decreto, pautaremos, na sequência, uma reflexão acerca da aproximação que vem se 
desenhando no cenário emergente entre o Estado e as chamadas empresas educacionais.

\section{O PNLD E OS SISTEMAS ESTRUTURADOS DE ENSINO:}

A EDUCAÇÃo SOB A LÓGICA DO MERCADO

[...] não se educa "para alguma coisa", educa-se porque a educação é um direito e, como tal, deve ser garantida de forma igualitária, equânime e justa. O objetivo da educação e das suas políticas não é formar gerações para o mercado, para o vestibular ou, tampouco, atingir os índices internacionais de alfabetização e matematização. O foco central são os sujeitos sociais, entendidos como cidadãos e sujeitos de direitos. (Gomes, 2012, p. 688)

Com essa instigante epígrafe trazida de Nilma Gomes, colocamo-nos a indagar sobre os riscos dos recentes avanços dos sistemas privados sobre a educação pública, notadamente no que diz respeito às disputas pelos recursos financeiros disponíveis nos programas educacionais de materiais didáticos, como o PNLD, por exemplo. Ao instaurar diversas possibilidades de acesso aos recursos públicos destinados à aquisição, avaliação e distribuição de materiais didáticos, o novo decreto do PNLD abre frestas para o ingresso dos sistemas estruturados de ensino, mais conhecidos como sistemas apostilados. Esses sistemas são organizados e controlados por empresas privadas do setor de educação, que produzem materiais didáticos estruturados e os comercializam não só com as redes privadas de ensino, mas também com as redes públicas dos municípios, especialmente os de pequeno e médio porte. Além de materiais destinados diretamente ao uso dos estudantes da educação básica, as chamadas apostilas, tais empresas oferecem cursos de capacitação e apoio pedagógico aos professores (de modo presencial e/ou a distância), e acesso a portais educativos, para professores e alunos.

$\mathrm{Na}$ mais elementar consulta aos sites de busca pode-se visualizar um apelo forte de alguns setores da grande mídia em favor dos sistemas estruturados. Em artigo publicado na revista Veja, Oliveira (2016, s. p.) anuncia em manchete: "Ensino estruturado: um modelo pedagógico eficaz". Na sequência, o cronista defende que "Ensinar de maneira intencional e estruturada não é sinônimo de ensino autoritário. Ao contrário: ensino estruturado melhora o 
desempenho". As condições de eficácia são garantidas, segundo o autor, pela organização sistemática e explícita do ensino, pelo uso de "estratégias didáticas robustas", mas especialmente pela possibilidade de controle prévio do trabalho do professor: "o que o professor faz é previamente estabelecido, e como reage às respostas dos alunos também obedece a um script mais ou menos flexível - dependendo da qualificação do professor". O material é entendido como dispositivo de controle e restrição da autonomia dos alunos e professores, pois, dentro desse espectro, os sistemas estruturados oferecem "materiais adequados e também o acompanhamento e suporte ao corpo docente por meio de mecanismos de supervisão e avaliação" (Oliveira, 2016, s. p.).

Na mesma direção, Becskeházy e Louzano (2010) apresentam um estudo financiado pela Fundação Lemann intitulado "Sala de aula estruturada: o impacto do uso de sistemas de ensino nos resultados da Prova Brasil. Um estudo quantitativo no estado de São Paulo", mostrando que 46\% dos municípios daquele estado adotavam sistemas estruturados de ensino no ano de 2010, sendo 34\% (505 mil alunos) em sistemas privados e 12\% (705 mil alunos) em sistemas públicos. Isso representava, à época, $50 \%$ da matrícula da rede municipal de ensino e $24 \%$ da matrícula de toda a rede pública daquele estado. Mas o que mais interessa recuperar desse estudo é o pressuposto, amplamente veiculado nessas mensagens, de que o professor é um profissional mal preparado. Dizem as pesquisadoras que "a preocupação primordial da Fundação Lemann é com a aquisição de conteúdos e habilidades formais” e, nessa direção, defendem que "o material didático realmente importa, especialmente quando os professores não estão preparados para a sala de aula” (Becskeházy; Louzano, 2010, s. p.).

As autoras explicam um suposto êxito dos sistemas estruturados em relação ao uso de livros didáticos oriundos do PNLD, sob os seguintes argumentos: 1) há maior exposição dos alunos aos conteúdos, na medida em que o professor não "pula" o conteúdo e ainda aprende o conteúdo que não dominava; 2) ocorre melhor aproveitamento do tempo na sala de aula, uma vez que se fazem menos cópias do quadro ao se usar o livro do aluno e a aula está mais bem estruturada e planejada no livro do professor; 3) os sistemas estruturados permitem maior controle do trabalho do professor pela direção e equipe, pelos pais e alunos; 4) por fim, há um forçoso alinhamento entre o material didático do aluno, as orientações ao professor e a capacitação docente. 
Note-se que na concepção educativa que rege tal lógica não se admitem ideias de autoria docente, não cabe reconhecer a importância da cultura local, das experiências sociais e do tempo próprio dos estudantes, nem tampouco incentiva-se a criação/recriação de dispositivos didático-pedagógicos para convergir a essas experiências. Os sistemas estruturados interferem fortemente na autonomia dos professores, sob a alegação de que estes não têm tempo, são mal preparados, gostam de soluções fáceis. Não por acaso tais sistemas são denominados "soluções educacionais" por aqueles que os vendem aos municípios. Não sendo consultados, de modo geral, sobre a aquisição desses sistemas, os professores acabam ficando reféns de roteiros rígidos, tornam-se aplicadores de materiais didáticos sobre os quais não têm ingerência e com os quais, muitas vezes, não têm nenhuma afinidade. É preciso registrar, todavia, o caso peculiar da prefeitura de Valinhos (SP), conforme apresentado por Cassiano (2013). Esse município, que adotava um sistema estruturado de ensino, fez consulta aos professores sobre a sua continuidade. A opção do corpo docente da rede municipal foi pelo retorno aos livros didáticos do PNLD em detrimento dos sistemas estruturados, sob diversos argumentos, em especial pela prerrogativa da liberdade de escolha e uso conferida aos professores e alunos.

Ao final do estudo de Becskeházy e Louzano (2010, s. p.) há um argumento conclusivo em favor dos sistemas estruturados, nestes termos: "Pesquisa da Fundação Lemann mostra que os professores brasileiros estão entre os 30\% de menor desempenho no Ensino Médio e que $80 \%$ deles têm mães com até quatro anos de educação". Ora, não se diz em relação a que ou a quem os professores brasileiros apresentam menor desempenho e ainda se desqualifica sua origem social ao culpabilizar as mães e sua não escolarização pelo suposto baixo desempenho. As autoras finalizam seus argumentos admitindo que "a mudança do perfil do professor depende de políticas estruturais na carreira docente e em maiores investimentos em educação, e, portanto, é de médio e longo prazo". Todavia, enquanto essas difíceis e profundas mudanças não acontecem, advogam que "a mudança na tecnologia de ensino pode trazer resultados no curto prazo [...] e pode começar agora" (Becskeházy; Louzano, 2010, s. p.). Parece que para fortalecer a defesa dos sistemas estruturados, apela-se para as soluções mais simplistas, lançando mão de uma perspectiva tecnicista, já há tempos refutada entre os pesquisadores da educação. 
Lembremos que no início da década de 1980, Saviani (1995, p. 23-24) apresentava o tecnicismo com este teor:

A partir do pressuposto da neutralidade científica e inspirada nos princípios de racionalidade, eficiência e produtividade, essa pedagogia advoga a reordenação do processo educativo de maneira a torná-lo objetivo e operacional [...]. Buscou-se planejar a educação de modo a dotá-la de uma organização racional capaz de minimizar as interferências subjetivas que pudessem pôr em risco sua eficiência. Daí a proliferação de propostas pedagógicas tais como o enfoque sistêmico, o microensino, o tele-ensino, a instrução programada, as máquinas de ensinar etc.

Na mesma perspectiva, Freitas (2016, s. p.) alerta para o chamado neotecnicismo, que retorna alicerçado em pressupostos da psicologia, neurociência, administração e informação, dentre outros, e se mostra "associado à mobilização do setor empresarial com amparo da mídia e reinserção na academia”, de modo a tornar-se hegemônico "como teoria pedagógica, executada em um espaço mercantilizado que atende tanto interesses ideológicos do grande capital internacional (OCDE), como aos interesses práticos de faturamento das indústrias e consultorias educacionais locais ou não".

Há outros aspectos a considerar, esses também relacionados com interesses mercadológicos, embora proliferem sob o discurso da qualidade. A padronização de conteúdos, metodologias, tempos e rotinas escolares visa ao alinhamento dos processos educativos com programas de avaliação de larga escala e monitoramento de resultados, sendo usada como sedução aos gestores dos municípios dos diversos estados brasileiros para suposto crescimento das notas do Ideb. Nesse sentido, incorre-se no fortalecimento da cultura de um tipo de avaliação em educação que confere ampla visibilidade aos resultados obtidos em testes padronizados e estabelece rankings de rendimento dos estudantes.

No contexto de municipalização do ensino fundamental, é preciso reconhecer que as prefeituras tiveram suas responsabilidades ampliadas no que diz respeito à organização curricular e pedagógica, embora nem sempre detivessem as condições técnicas e políticas para tal, o que pode explicar a sedução dos gestores pelos sistemas estruturados. Todavia, Adrião et al. (2009, p. 806807) alertam para um conjunto de problemas nessa relação entre a educação pública e os sistemas de ensino privado, tais como: "falta de controle social ou técnico, fragilidade conceitual e pedagógica dos materiais e serviços comprados 
pelos municípios, duplo pagamento pelo mesmo serviço, vinculação do direito à qualidade de ensino submetida à lógica do lucro e padronização/homogeneização de conteúdos e currículos escolares como parâmetro de qualidade”.

Esse aspecto do duplo emprego de recursos públicos na mesma finalidade evidencia o histórico problema da má gestão do orçamento da educação. Ao aderirem aos sistemas estruturados de ensino e declinarem da participação no PNLD, os municípios oneram duas vezes o contribuinte pelo material didático, uma vez que "a população já remunera empresas privadas do setor editorial, triadas por avaliação técnica para a produção de livros didáticos que integram os programas federais e cujo acervo está disponível gratuitamente às redes municipais de ensino" (Adrião et al., 2009, p. 809). Esses recursos poderiam, então, ser investidos em outras tantas demandas que compõem o cenário da educação municipal, como educação infantil, remuneração docente, tempo integral e infraestrutura das escolas, e assim contribuir de maneira mais eficaz para a melhoria dos processos educativos locais.

Há que se considerar, ainda, a diferença de custo do material entre os sistemas estruturados e o PNLD. Por ser adquirido em larga escala, o custo unitário do livro didático é bem inferior aos preços dos livros praticados no mercado. Britto (2011, p. 14) registrava que o custo médio dos sistemas estruturados para os municípios que aderem é de $\mathrm{R} \$ 150,00$ por aluno/ano, ao passo que no âmbito do PNLD, "no caso do ensino médio, por exemplo, para cada aluno são destinados sete livros reutilizáveis e quatro livros consumíveis, o que significaria um custo estimado de R $\$ 41,00$ por aluno por ano". Some-se a isso o fato de que nem sempre há lisura nos processos de aquisição de tais sistemas. Britto (2011) salienta que até o ano de 2007 a maioria dos municípios paulistas contratava sem licitação, adotando o vago critério de notória especialização. Desde então, o Tribunal de Contas do Estado estabeleceu a exigência da licitação para a compra de sistemas de ensino. Não obstante, segundo esta autora, a maioria das licitações se dá a partir de carta-convite, o que não impede que ocorra "algum tipo de direcionamento, por meio do detalhamento dos serviços educacionais a serem prestados pelas contratadas” (Britto, 2011, p. 15).

É importante destacar, ainda, as preocupações dos pesquisadores quanto à qualidade conceitual e pedagógica dos materiais disponibilizados pelos sistemas estruturados que, ao contrário dos materiais submetidos ao PNLD, não passam por quaisquer formas de avaliação sistemática e oficial, com base em critérios 
anunciados publicamente por meio de edital. Como resultado dessa situação, encontram-se "sérios problemas conceituais e gráficos em apostilas de sistemas de ensino, além da utilização de abordagens pedagógicas descontextualizadas e excessivamente esquemáticas, herdeiras da orientação para o vestibular que caracterizou o surgimento desse tipo de material" (Britto, 2011, p. 14).

Diversos pesquisadores (Moya, 2012; Cária, 2012; Cain, 2014; Nascimento, 2015) têm se dedicado a analisar, com base em fontes consistentes e em rigorosas abordagens metodológicas, os impactos da contratação/adoção de sistemas estruturados de ensino pelas redes municipais no desempenho de estudantes e no trabalho pedagógico dos professores. De modo geral, esses estudos demonstram a falta de evidência efetiva de um melhor rendimento dos estudantes naquelas redes públicas que fazem uso de sistemas estruturados, em relação às que adotam livros didáticos distribuídos no âmbito do PNLD. Podemos referir, nessa direção, a pesquisa de Moya (2012), que investiga os resultados da Prova Brasil no período 2005-2009 entre estudantes do ensino fundamental de municípios que contratam sistemas estruturados de ensino. Essa autora declara que não encontrou "resultados conclusivos sobre o impacto diferenciado dos métodos em alunos com níveis de proficiência iniciais distintos", e ainda afirma que "sobre a contribuição dos métodos estruturados na homogeneização do desempenho dos municípios na Prova Brasil, os resultados obtidos não possuem robustez suficiente para nos permitir afirmar a existência deste efeito" (Moya, 2012, p. 39).

Nascimento (2015), por sua vez, compara resultados obtidos na Prova Brasil entre 1.817 escolas, de 282 municípios, algumas que aderem aos Sistemas Apostilados de Ensino e outras que adotam livros didáticos do PNLD, no período de 2004 a 2011. Como conclusão final desse amplo estudo, a autora afirma que o fato de adotar Sistemas Apostilados de Ensino (SAE) ao invés de livros didáticos (LD), não propicia melhores resultados na Prova Brasil, tendo sido demonstrado em análise estatística de âmbito nacional que "em longo prazo as escolas que utilizam LD apresentaram taxa de crescimento superior na Prova Brasil em comparação com escolas que utilizam SAE" (Nascimento, 2015, p. 121).

Por fim, referimos o estudo de Cain (2014), que analisou como o uso do sistema apostilado de ensino interfere na organização do trabalho pedagógico em duas escolas públicas de ensino fundamental de um município paulista, entre 2009 e 2012. Essa autora constata que o sistema apostilado adotado pelo 
município, em parceria público-privado, acaba por se sobrepor aos projetos político-pedagógicos das escolas, instituindo formas de organização do trabalho pedagógico que desconsideram tais projetos e evidenciam o viés da padronização do ensino. Cain (2014, p. 296-297) demonstra ainda que houve "desconsideração quanto ao fato de que as escolas são diferentes umas das outras, possuem características e peculiaridades próprias; as salas de aulas possuem diversidade, os alunos são singulares quanto ao ritmo e à forma de aprender". A autora reconhece que, a despeito do caráter prescritivo e impositivo dos sistemas apostilados, as escolas não deixam de gestar as suas próprias estratégias de organização do trabalho pedagógico e, assim, criar possibilidades de exercer algum grau de autonomia escolar.

\section{CONSIDERAÇÕES FINAIS}

Para concluir, retomemos as palavras de Nilma Gomes (2012) expostas na epígrafe da seção anterior, quando essa autora reafirma a educação como um direito que deve ser garantido de forma igualitária, equânime e justa, ultrapassando largamente objetivos imediatistas de formar gerações para o mercado de trabalho, o vestibular, o Enem e a Prova Brasil, dentre outros. Se concordamos que "o foco central são os sujeitos sociais, entendidos como cidadãos e sujeitos de direitos” (Gomes, 2012, p. 688), dessa hercúlea tarefa educacional deve se ocupar o Estado e não a iniciativa privada.

No processo tenso e complexo de escolarização/disciplinarização das práticas culturais e dos saberes científicos de referência, os materiais didáticos adquiridos pelo Estado e disponibilizados às escolas de educação básica precisam ser submetidos a mecanismos sistemáticos e rigorosos de avaliação, sob o crivo de professores e pesquisadores, da escola e da universidade, como vinha sendo realizado no âmbito do PNLD até o ano de 2016. Sobre o desempenho dos estudantes incidem fatores de ordem social, cultural, econômica e pedagógica que vão muito além do material didático, portanto, este não pode ser considerado parâmetro de desempenho em avaliações de larga escala. Também é preciso reconhecer a prerrogativa legal prevista na Constituição Federal de 1988, em que se afirma a responsabilidade estrita do Estado brasileiro frente ao atendimento dos estudantes na educação básica, por meio de programas 
suplementares de material didático-escolar, transporte, alimentação e assistência à saúde.

A avaliação institucional dos livros didáticos protagonizada pelo MEC e pelas universidades no âmbito do PNLD, ainda que sujeita a inúmeras críticas e indicações de melhorias, tem sinalizado um conjunto de características editoriais e pedagógicas que vêm qualificando progressivamente a produção didática. De outra parte, os sistemas estruturados e suas apostilas não passam por processos avaliativos públicos; restringem a autonomia docente; desconsideram as necessidades locais e as especificidades dos projetos político-pedagógicos escolares; submetem o ensino e a aprendizagem a um tempo delimitado e a uma sequência predeterminada; não são escolhidos pelos professores e estudantes e sim pelas equipes gestoras; têm custo de aquisição alto, em razão da pequena quantidade; promovem a transferência de recursos públicos para empresas privadas; são pagos duplamente pelo contribuinte, uma vez que os livros didáticos são distribuídos gratuitamente aos municípios com verbas do governo federal.

A lógica mercadológica e economicista que avança sobre o cenário educacional vem se apropriando do sentido do conceito de qualidade em educação, impondo uma perspectiva gerencial movida sob os argumentos dos empresários educacionais. Tendo em vista o acelerado crescimento da lógica gerencial sobre a educação manifestada, por exemplo, na Reforma do Ensino Médio e na configuração da Base Nacional Comum Curricular (BNCC), receia-se que o PNLD seja apropriado, para além dos oligopólios já estabelecidos pelas grandes editoras, como espaço de reprodução do capital pelos sistemas estruturados de ensino e suas "soluções educacionais".

\section{REFERENNCIAS}

ADRIÃO, Theresa; GARCIA, Teise; BORGHI, Raquel; ARELARO, Lisete. Uma modalidade peculiar de privatização da educação pública: a aquisição de "sistemas de ensino" por municípios paulistas. Educação e Sociedade, Campinas, v. 30, n. 108, p. 799-818, out. 2009.

BECSKEHÁZY, Ilona; LOUZANO, Paula. Sala de aula estruturada: o impacto do uso de sistemas de ensino nos resultados da Prova Brasil - um estudo quantitativo no estado de São Paulo. 2010. Disponível em: https://docplayer.com.br/35941910-Sala-de-aula-estruturada.html. Acesso em: 15 ago. 2017. 
BRASIL. Constituição da República Federativa do Brasil (1988). Disponível em: http:// legis.senado.leg.br/legislacao/ListaTextoSigen.action?norma $=579494 \&$ id $=164348$ 03\&idBinario=16434817. Acesso em: 15 jul. 2018.

BRASIL. Presidência da República. Decreto n 7.084, de 27 de janeiro de 2010. Disponível em: http://www.planalto.gov.br/ccivil_03/_Ato2007-2010/2010/ Decreto/D7084.htm. Acesso em: 18 maio 2018.

BRASIL. Presidência da República. Decreto no 9.099, de 18 de julho de 2017. Disponível em: http://www.planalto.gov.br/ccivil_03/_ato2015-2018/2017/decreto/D9099.htm. Acesso em: 22 jul. 2018.

BRITTO, Tatiana Feitosa de. O livro didático, o mercado editorial e os sistemas de ensino apostilados. Brasília: Centro de Estudos da Consultoria do Senado Federal, jun. 2011. (Textos para discussão, 92). Disponível em: https://www12.senado.leg.br/ publicacoes/estudos-legislativos/tipos-de-estudos/textos-para-discussao/td-92-o-livro-didatico-o-mercado-editorial-e-os-sistemas-de-ensino-apostilados. Acesso em: 22 jul. 2018.

CAIMI, Flávia Eloisa. O livro didático de história e suas imperfeições: repercussões do PNLD após 20 anos. In: ROCHA, Helenice A. B.; REZNIK, Luís; MAGALHÃES, Marcelo (org.). Livros didáticos de História: entre políticas e narrativas. Rio de Janeiro: Ed. FGV, 2017. v. 1, p. 23-45.

CAIN, Alessandra Aparecida. A organização do trabalho pedagógico na escola e o sistema apostilado de ensino: estudo de caso. 2014. Tese (Doutorado) - Faculdade de Ciências e Letras, Universidade Estadual Paulista "Júlio de Mesquita Filho" (Unesp). Araraquara, 2014.

CÁRIA, Neide Pena. A parceria de empresas educacionais de iniciativa privada com as redes municipais de educação do Sul de Minas Gerais. 2012. Tese (Doutorado) Programa de Estudos Pós-Graduados em Educação: Currículo, Pontifícia Universidade Católica de São Paulo (PUC-SP). São Paulo, 2012.

CASSIANO, Célia Cristina de F. Sistemas estruturados de ensino e mercado editorial brasileiro. In: CONGRESSO BRASILEIRO DE CIÊNCIAS DA COMUNICAÇÃO, 36., 2013, Manaus. Anais... p. 1-12. Disponível em: http://www.intercom.org.br/ papers/nacionais/2013/resumos/R8-1996-1.pdf. Acesso em: 20 jan. 2019.

DI GIORGI, Cristiano Amaral G. et al. Uma proposta de aperfeiçoamento do PNLD como política pública: o livro didático como capital cultural do aluno/família. Ensaio: Avaliação e Políticas Públicas em Educação, Rio de Janeiro, v. 22, n. 85, p. 1027-1056, out./dez. 2014.

ESCOLANO BENITO, Agustín (ed.). Curriculum editado y sociedade del conocimiento: texto, multimedialidad y cultura de la escuela. Valencia: Tirant Lo Blanch, 2006.

FREITAS, Luiz Carlos de. Tecnicismo: ele está de volta. Avaliação Educacional - Blog do Freitas. S. 1., 26 ago. 2016. Disponível em: https://avaliacaoeducacional. com/2016/08/26/tecnicismo-ele-esta-de-volta/. Acesso em: 20 jul. 2018. 
GOMES, Nilma Lino. Apresentação. Desigualdades e diversidade na educação. Educação \& Sociedade, Campinas, v. 33, n. 120, p. 687-693, jul./set. 2012. Disponível em: http://www.cedes.unicamp.br. Acesso em: 10 jul. 2018.

HÖFLING, Eloisa de Mattos. Notas para discussão quanto à implementação de programas de governo: em foco o Programa Nacional do Livro Didático. Educação \& Sociedade, ano XXI, n. 70, p. 159-170, abr. 2000. Disponível em: http://www.scielo. br/pdf/es/v21n70/a09v2170.pdf. Acesso em: 12 nov. 2015.

LAVILLE, Christian. A guerra das narrativas: debates e ilusões em torno do ensino de História. Revista Brasileira de História, São Paulo: Anpuh, v. 19, n. 38, p. 125-138, 1999.

MOYA, Sarah Helena. Avaliação da eficácia dos métodos estruturados de ensino nas escolas públicas municipais do estado de São Paulo. 2012. Dissertação (Mestrado)

- Escola de Economia de São Paulo, Fundação Getulio Vargas. São Paulo, 2012.

NASCIMENTO, Karine Bueno do. Programa Nacional do Livro Didático e Sistemas Apostilados de Ensino: um diálogo mediado pelas evidências da Prova Brasil. 2015. Dissertação (Mestrado) - Programa de Pós-Graduação em Educação em Ciências: Química da Vida e Saúde, Universidade Federal de Santa Maria (UFSM). Santa Maria, 2015.

OLIVEIRA, João Batista. Ensino estruturado: um modelo pedagógico eficaz. Veja, São Paulo, 30 mar. 2016. Disponível em: https://veja.abril.com.br/blog/educacao-em-evidencia/ensino-estruturado-um-modelo-pedagogico-eficaz/. Acesso em: 10 jul. 2018.

RAMOS, Marise N.; FRIGOTTO, Gaudêncio. Medida Provisória 746/2016: A contra-reforma do ensino médio do golpe de Estado de 31 de agosto de 2016. HISTEDBR on-line, Campinas, n. 70, p. 30-48, dez. 2016.

SAVIANI, Dermeval. Escola e democracia. Polêmicas do nosso tempo. 30. ed. Campinas: Autores Associados, 1995.

\section{NOTAS}

${ }^{1}$ Doutora em Educação (UFRGS). Pós-doutora pela Flacso/Argentina.

2 Disponível em: http://www.fnde.gov.br/programas/programas-do-livro/livro-didatico/ dados-estatisticos. Acesso em: 24 jul. 2018.

${ }^{3}$ Embora não seja o alvo do presente estudo, essa avaliação crítica dos limites do Programa é de extrema importância e pode ser visualizada em outros estudos, como BRITTO (2011) e DI GIORGI et al. (2014).

Artigo recebido em 31 de outubro de 2018. Aprovado em 12 de fevereiro de 2019. 